\title{
Dinâmica da comunidade fitoplanctônica e aspectos sanitários de um lago urbano eutrófico em São Paulo, SP
}

\author{
Regina Célia Gentil ${ }^{1,2}$, Andréa Tucci ${ }^{1}$ e Célia Leite Sant'Anna ${ }^{1}$
}

Recebido: 07.06.2005; aceito: 06.06.2008

\begin{abstract}
Phytoplankton community dynamics and sanitary aspects of a eutrophic urban lake, São Paulo, SP). Phytoplanktonic algae are important in water quality assessment reflecting ecossystem dynamics. Our main purpose was to study the seasonal variation of the phytoplankton community and its relations with physical and chemical parameters of the water and coliforms from Lago das Garças (Instituto de Botânica, São Paulo, SP, Brazil). The samples for the study of the physical and chemical parameters and phytoplankton analyses were collected monthly (January 1997 to March 1998) in three depths (surface, $2 \mathrm{~m}$ and bottom). The phytoplankton community was studied taking into account the biomass (chlorophyll- $a$ ), density and biological index. The phytoplankton was represented by 214 taxa distributed in nine taxonomic classes. Chemical parameters showed vertical and seasonal distribution whereas the phytoplankton presented a seasonal pattern; four species of Cyanobacteria were dominant mostly in the summer (Cylindrospermopsis raciborskii (Woloszynska) Seenayya \& Subba Raju, Sphaerocavum brasiliense M.T.P. Azevedo \& C.L. Sant'Anna, Merismopedia glauca (Ehrenberg) Kützing and Merismopedia tenuissima Lemmermann).
\end{abstract}

Key words: eutrophication, phytoplankton, seasonal variation, water quality

RESUMO - (Dinâmica da comunidade fitoplanctônica e aspectos sanitários de um lago urbano eutrófico, São Paulo, SP). Algas fitoplanctônicas são importantes na avaliação da qualidade da água, refletindo a dinâmica do ecossistema. O objetivo principal foi verificar a variação sazonal do fitoplâncton, relacionando-a com parâmetros físicos e químicos da água e coliformes do Lago das Garças (Instituto de Botânica, São Paulo, SP, Brasil). Amostras de água para análise das variáveis físicas e químicas e do fitoplâncton foram coletadas mensalmente (janeiro/97 a março/98) em três profundidades (superfície 2 metros e fundo). A comunidade fitoplanctônica foi analisada através da sua biomassa (clorofila- $a$ ), da sua densidade e dos índices biológicos. Foram identificados 214 táxons distribuídos em nove classes taxonômicas. As variáveis químicas tiveram variação vertical e temporal enquanto que o fitoplâncton apresentou padrão sazonal; quatro espécies de Cyanobacteria (Cylindrospermopsis raciborskii (Woloszynska) Seenayya \& Subba Raju, Sphaerocavum brasiliense M.T.P. Azevedo \& C.L. Sant'Anna, Merismopedia glauca (Ehrenberg) Kützing e Merismopedia tenuissima Lemmermann) dominaram, principalmente nos meses mais quentes.

Palavras-chave: eutrofização, fitoplâncton, qualidade da água, variação sazonal

\section{Introdução}

O uso múltiplo da água vem aumentando significativamente em todo o mundo, com conseqüiente comprometimento de sua qualidade para os diversos valores e serviços, ocasionando alterações de habitats, da biodiversidade, da pesca comercial e esportiva e da quantidade de água (Margalef 1991, Tundisi 2003).

No Brasil, especialmente no Estado de São Paulo, vários reservatórios encontram-se eutrofizados, com a qualidade de suas águas deteriorada, afetando a vida dos organismos que neles habitam (CETESB 2000, Carvalho 2003).

Segundo Margalef (1983), organismos planctônicos funcionam como "sensores refinados das propriedades ambientais" refletindo a dinâmica do ecossistema. Assim sendo, são importantes os estudos de avaliação da qualidade da água que incluam análises qualitativa e quantitativa desses organismos (Tundisi 2003).

Em relação às algas fitoplanctônicas é importante ressaltar que sua presença na água doce constitui elemento importante para avaliação das condições ambientais. Segundo Stevenson \& Smol (2003), diversos estudos sobre algas como indicadores de qualidade da água foram realizados em várias partes do mundo desde o começo do século passado, tendo nos últimos anos a implantação de muitos programas de monitoramento utilizando o fitoplâncton como um dos principais parâmetros na avaliação ambiental.

1. Instituto de Botânica, Caixa Postal 3005, 01061-970 São Paulo, SP, Brasil

2. Autor para correspondência: rebiogentil@yahoo.com.br 
A composição taxonômica e a diversidade da comunidade fitoplanctônica são utilizadas para avaliar a saúde do ambiente e inferir as prováveis causas de danos ecológicos.

Há várias décadas, o Lago das Garças que é o objeto do presente estudo, vem recebendo despejos de esgotos domésticos "in natura", provenientes das instituições localizadas nas suas proximidades, ainda que esteja inserido dentro de um parque (Sant'Anna et al. 1989, Carmo et al. 2002, Bicudo et al. 2006). Este processo de intensa eutrofização tem acarretado sérios problemas de deterioração da qualidade da água, de proliferações de aguapé e de florações de cianobactérias (Sant'Anna et al. 1989, Nogueira 1997, Sant'Anna et al. 1997, Bicudo et al. 1999a, 2006).

Desta forma, o Lago das Garças vem sendo estudado há vários anos em relação à comunidade fitoplanctônica e às variáveis ambientais (Sant'Anna et al. 1989, Nogueira 1997, Sant'Anna et al. 1997, Azevedo \& Sant'Anna 1999, Bicudo et al. 1999a, 1999b, Vercellino 2001, Ramírez \& Bicudo 2002, 2003, 2005, Tucci 2002, Tucci \& Sant'Anna 2003, Crossetti \& Bicudo 2005a, 2005b, Fonseca 2005, Crossetti 2006, Tucci et al. 2006). Além destes, há ainda um trabalho relativo à detecção de microcistina de uma cepa de Microcytis aeruginosa (Kützing) Kützing isolada deste ambiente (Azevedo et al. 1994) e outro sobre estudos em cultura de cianobactérias de lagos do Parque Estadual das Fontes do Ipiranga (PEFI), inclusive o Lago das Garças (Honda \& Azevedo 2004).

O principal objetivo deste trabalho foi analisar a dinâmica da comunidade fitoplanctônica ao longo de um ciclo sazonal e suas relações com variáveis físicas e químicas da água, bem como avaliar a qualidade sanitária da água.

\section{Material e métodos}

O Lago das Garças localiza-se na região sul do município de São Paulo e está situado no Parque Estadual das Fontes do Ipiranga (23⒊ $38^{\prime} 08^{\prime} \mathrm{S}$ $23^{\circ} 40^{\prime} 18^{\prime \prime} \mathrm{S}$ e 46 $36^{\circ} 48^{\prime \prime} \mathrm{W}-46^{\circ} 38^{\prime} 00^{\prime \prime} \mathrm{W}$ ) (Fernandes et al. 2002). Possui profundidade máxima de $4,7 \mathrm{~m}$, profundidade média de $2,1 \mathrm{~m}$, volume aproximado de $188.785 \mathrm{~m}^{3}$ e área de $88.156 \mathrm{~m}^{2}$ (Bicudo et al. 2002). O clima da região é do tipo Cwb que significa clima temperado com inverno seco e verão chuvoso, apresentando temperatura e precipitação médias anuais de $19^{\circ} \mathrm{Ce} 1.540 \mathrm{~mm}$, respectivamente (Santos $\&$ Funari 2002).
As coletas foram realizadas mensalmente, entre janeiro/1997 a março/1998, na estação correspondente a região mais profunda do lago $(4,7 \mathrm{~m})$, em três profundidades: superfície, dois metros e fundo. As amostras para as análises físicas, químicas e biológicas da água foram obtidas com garrafa coletora do tipo Van Dorn.

Foram avaliados a temperatura da água com termistor (de $10 \mathrm{em} 10 \mathrm{~cm}$ ), transparência com disco de Secchi, turbidez com turbidimeto (Digimed), condutividade com condutivimetro, oxigênio dissolvido segundo Golterman et al. (1978), $\mathrm{pH}$ com pHmetro, alcalinidade segundo Golterman \& Clymo (1969), nitrato segundo Mackereth et al. (1978), nitrito segundo Golterman et al. (1978), amônio segundo Solorzano (1969), ortofosfato e fósforo total dissolvido segundo Strickland \& Parsons (1960), silicato segundo Golterman et al. (1978) e, nitrogênio e fósforo totais segundo Valderrama (1981). A zona eufótica foi estimada multiplicando por 3 os valores de transparência da água (Cole 1983). Análise de clorofila-a foi realizada segundo Sartory \& Grobelaar (1984) com cálculos de acordo com Wetzel \& Likens (1991).

As amostras para colimetria (NMP org $100 \mathrm{~mL}^{-1}$ ) foram coletadas em dois períodos: inverno (julho e agosto de 1997) e verão (fevereiro e março de 1998) e, para as análises de demanda bioquímica de oxigênio - DBO e demanda química de oxigênio - DQO, as amostras foram coletadas nos períodos de primavera (setembro e outubro de 1997) e verão (fevereiro e março de 1998). Para as determinações colimétricas, de $\mathrm{DBO}_{(5,20)}$ e DQO seguiu-se APHA (1989).

As amostras para as análises qualitativas do fitoplâncton foram coletadas com rede de plâncton com abertura de malha de $20 \mu \mathrm{m}$ e preservadas com formol 4\%. As análises taxonômicas foram realizadas com auxílio de microscópio binocular, com câmara clara, ocular de medição e câmara fotográfica acopladas ao sistema óptico.

As amostras para as analises quantitativas do fitoplâncton foram preservadas com lugol acético $1 \%$. A contagem dos organismos foi feita de acordo com o método de Utermöhl (1958), em microscópio invertido Carl Zeiss, em aumento de 400 vezes, sendo cada célula, colônia, cenóbio ou filamento considerados como um indivíduo. Em cada contagem foram traçadas duas linhas perpendiculares a partir do centro da câmara e os campos contados foram determinados de acordo com cada amostra, considerando-se campos alternados. O número de campos contados foi definido com base em dois critérios: a contagem de 100 
indivíduos da espécie mais abundante e a estabilização da curva de rarefação de espécies.

As espécies foram classificadas como dominantes e abundantes de acordo com os critérios de Lobo \& Leighton (1986). Aquelas que contribuíram com mais de $50 \%$ da densidade total de cada amostra foram classificadas como dominantes e, as abundantes foram aquelas cuja densidade foi superior a densidade média da amostra.

A partir das análises quantitativas foram calculados os seguintes índices biológicos: Riqueza (Margalef 1958), Diversidade (Shannon \& Weaver 1979), Equitabilidade (Pielou 1975) e Dominância (Simpson 1949).

Para análise estatística descritiva dos dados utilizouse média e desvio padrão. A ordenação das unidades amostrais no tempo e no espaço foi feita pela análise de componentes principais (PCA) utilizando matriz de covariância no Programa PC-ORD versão 3.1 para Windows (McCune \& Mefford 1997). Os dados foram previamente padronizados pela amplitude de variação utilizando-se transformação "ranging" para variáveis abióticas e " $\log (\mathrm{x}+1)$ " para variáveis biológicas. As transformações dos dados foram feitas utilizando-se o programa FITOPAC (Shepherd 1996).

\section{Resultados e Discussão}

A distribuição das unidades amostrais e as associações com as variáveis limnológicas estudadas, bem como o perfil térmico da coluna d'água e a variação mensal da precipitação e da temperatura do ar, estão apresentadas nas figuras 1 a 3 , respectivamente.

A análise de componentes principais (ACP) para os dados abióticos e clorofila $a$ resumiu $56 \%$ da variabilidade total dos dados nos dois primeiros eixos (tabela 1, figura 1). No lado negativo do eixo 1 foram alocadas a maioria das unidades amostrais relativas ao final da primavera e verão (novembro/97 a março/98), associadas aos maiores valores de alcalinidade, amônio, condutividade elétrica, ortofosfato, fósforo total dissolvido, silicato, nitrogênio total e aos menores valores de oxigênio dissolvido. Todas as demais unidades amostrais posicionaram-se no lado positivo do eixo 1, associadas aos elevados teores de oxigênio dissolvido.

O eixo 1 da PCA (figura 1) demonstrou uma distribuição vertical heterogênea das unidades amostrais da primavera e do verão (novembro/97 a março/98), associadas aos baixos valores de oxigênio dissolvido e aos altos valores de amônio,

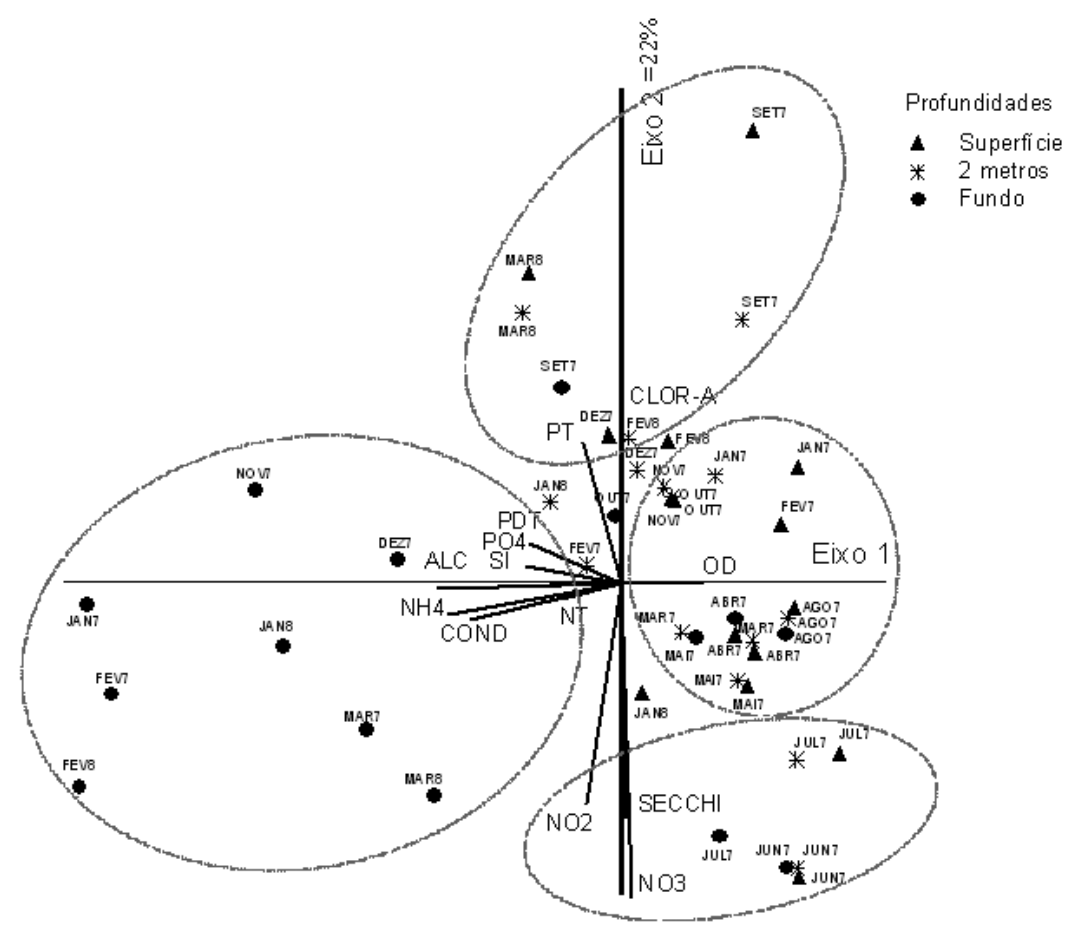

Figura 1. Biplot da ACP (eixos 1 e 2) das unidades amostrais (abreviações: JAN7 a MAR8), em três profundidades (superfície, 2 m e fundo) no Lago das Garças, em função das variáveis limnológicas. (Abreviações conforme tabela 1). 


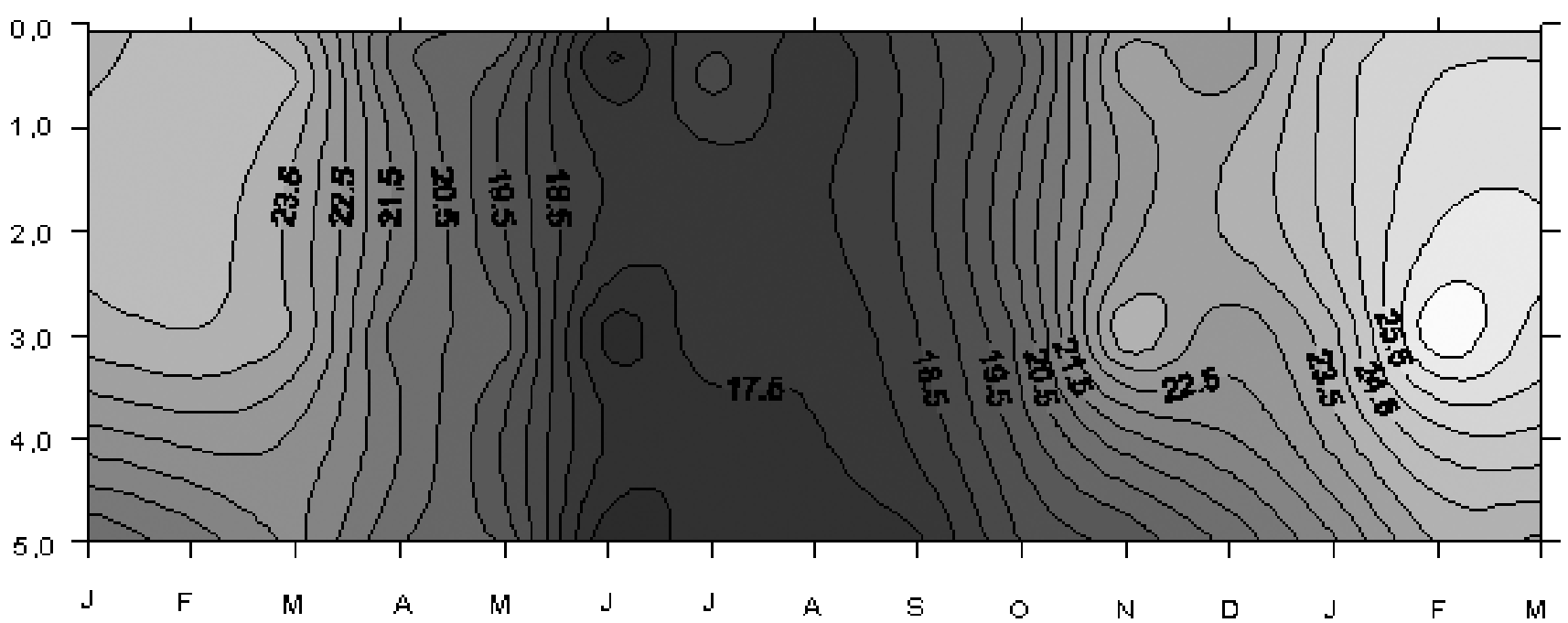

Figura 2. Diagrama de profundidade e tempo das isolinhas de temperatura da água no Lago das Garças durante o período estudado.

condutividade e alcalinidade. Nesse período foi registrada estratificação térmica (figura 2). Vários trabalhos realizados no mesmo ambiente também verificaram relação da estratificação térmica com baixas concentrações de oxigênio dissolvido e altos valores de condutividade no fundo, possivelmente pela maior quantidade de amônio oriundo do processo de decomposição (Moura 1996, Ramirez 1997, Bicudo et al. 1999a, Ramirez \& Bicudo 2002, 2003). Nessa porção da coluna d'água, muito provavelmente, a ação de decompositores libera amônio e eleva a concentração iônica o que reflete na condutividade (Wetzel 1993). Isso mostra a maior importância da escala vertical na variabilidade limnológica do sistema em período de estratificação.

No lado positivo do eixo 2 , estão agrupadas as unidades amostrais de superfície e 2 metros da primavera-verão (janeiro-fevereiro/97, setembro a dezembro/97 e março/98), associadas aos maiores

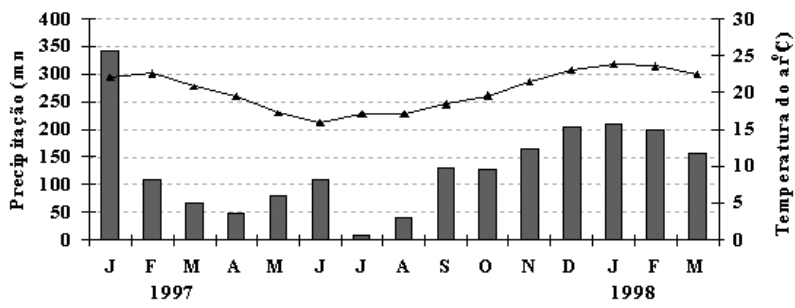

Figura 3. Variação da precipitação média mensal (mm) e temperatura do ar $\left({ }^{\circ} \mathrm{C}\right)$ no local de estudo $(\square=$ Precipitação; $\longrightarrow-=$ Temperatura do ar).
Tabela 1. Coeficientes de correlação de Pearson entre as variáveis físicas e químicas da água analisadas com os dois primeiros eixos da $\mathrm{ACP}$ (valores em negrito correspondem às variáveis que tiveram maior correlação com os eixos, acima de 0,5 ).

\begin{tabular}{|c|c|c|c|}
\hline \multirow[b]{2}{*}{ Variáveis } & \multirow[b]{2}{*}{ Abreviações } & \multicolumn{2}{|c|}{$\begin{array}{c}\text { Componentes } \\
\text { principais }\end{array}$} \\
\hline & & Eixo 1 & Eixo 2 \\
\hline Temperatura & TEMP & $-0,268$ & 0,367 \\
\hline Transparência & SECCHI & 0,140 & $-0,721$ \\
\hline Turbidez & TUR & $-0,331$ & 0,353 \\
\hline Condutividade & COND & $-0,845$ & $-0,290$ \\
\hline Oxigênio dissolvido & OD & 0,671 & 0,075 \\
\hline $\mathrm{pH}$ & $\mathrm{PH}$ & 0,418 & 0,164 \\
\hline Alcalinidade & ALC & - 0,932 & $-0,110$ \\
\hline Nitrogênio total & NT & $-0,536$ & - 0,195 \\
\hline Amônio & NH4 & $-0,905$ & $-0,272$ \\
\hline Nitrito & $\mathrm{NO} 2$ & $-0,409$ & - 0,700 \\
\hline Nitrato & NO3 & 0,231 & - $\mathbf{0 , 8 3 3}$ \\
\hline Fósforo total & PT & $-0,421$ & 0,562 \\
\hline $\begin{array}{l}\text { Fósforo total } \\
\text { dissolvido }\end{array}$ & PDT & $-0,654$ & 0,302 \\
\hline Ortofosfato & PO4 & - 0,680 & 0,209 \\
\hline Silicato & $\mathrm{Si}$ & $-\mathbf{0 , 5 7 9}$ & $-0,042$ \\
\hline \multirow[t]{2}{*}{ Clorofila- $a$} & CLOR-A & $-0,018$ & 0,567 \\
\hline & ação explicada & $34 \%$ & $22 \%$ \\
\hline
\end{tabular}


valores de clorofila- $a$, fósforo total e oxigênio dissolvido (figuras 1, 4). Destacam-se, neste período, elevadas densidades de cianobactérias em relação às demais classes (figura 5). Isso evidencia a influência biológica sobre algumas variáveis abióticas, como altos valores de oxigênio dissolvido (tabela 2), diminuição da transparência da água (figura 6) e aumento de fósforo total (tabela 2). Florações de cianobactérias também foram registradas na primavera e verão por outros autores nesse reservatório (Sant'Anna et al. 1989, Nogueira 1997, Ramirez \& Bicudo 2002, 2003, Fonseca 2005 e Crossetti 2006) caracterizando a ocorrência sazonal das florações na primavera e verão.

No lado negativo do eixo 2 (figura 1) foram agrupadas as unidades amostrais referente ao inverno (junho-julho/97) independentemente das profundidades, associadas aos maiores valores de nitrato, nitrito e transparência da água. Neste período foi registrado mistura da coluna d'água (figura 2), refletindo os valores mais homogêneos dos compostos nitrogenados. Além disso, também foi registrada baixa densidade de Cyanobacteria na superfície, que resultou em valores máximos de transparência (figura 6).

Em relação à comunidade fitoplanctônica, foram identificados 214 táxons distribuídos em nove classes, sendo Chlorophyceae a que mais contribuiu com a riqueza de espécies, seguida de Cyanobacteria (figura 7).

As classes Chlorophyceae e Cyanobacteria, que contribuíram de forma expressiva para a riqueza e densidade do fitoplâncton no Lago das Garças, são amplamente distribuídas em ambientes tropicais eutrofizados (Sant'Anna et al. 1997, Huszar et al. 2000, Komárek 2003, Shubert 2003). A ordem Chlorococcales (Chlorophyceae), que neste trabalho foi muito representativa em termos de riqueza de espécies, é referida por outros autores como o grupo

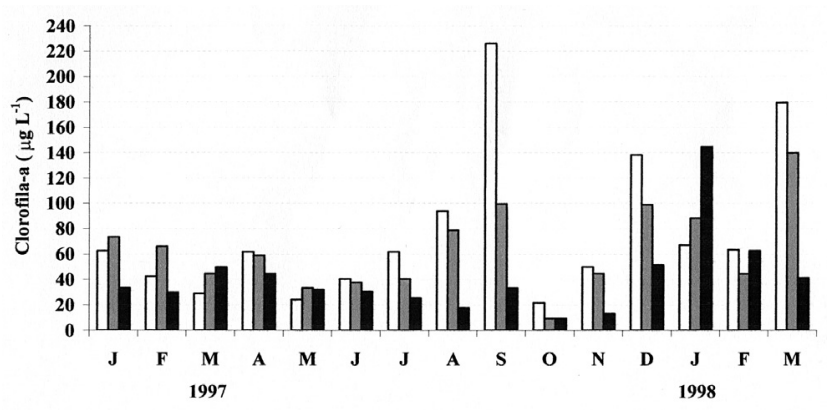

Figura 4. Variação espacial e temporal da clorofila- $a\left(\mu \mathrm{g} \mathrm{L}^{-1}\right)$ no Lago das Garças durante o período estudado $(\square=$ superfície; $\square=2$ metros; $\mathbf{\square}$ = fundo). que mais contribui para a riqueza total do fitoplâncton em águas tropicais brasileiras eutrofizadas (Beyruth 1996, Bicudo et al. 1999a, Fonseca 2006, PintoCoelho et al. 1999, Sant'Anna et al. 1997, Tucci et al. 2006).

Durante o período de verão, com estratificação térmica da coluna d'água (figura 2), foram registradas elevadas densidades de cianobactérias (figura 5) e algumas espécies foram classificadas como dominantes: Cylindrospermopsis raciborskii (Woloszynska) Seenayya \& Subba Raju na superfície; Sphaerocavum brasiliense M.T.P. Azevedo \& C.L. Sant'Anna e Merismopedia glauca (Ehrenberg) Kützing em todas as profundidades; Merismopedia tenuissima Lemmermann a 2 metros de profundidade e no fundo (figura 8). As estratégias adaptativas que algumas cianobactérias apresentam, tais como, intensa divisão celular nos meses mais quentes, fixação de nitrogênio atmosférico (formas heterocitadas) e presença de aerótopos, conferem-lhes vantagens competitivas sobre os demais grupos fitoplanctônicos (Reynolds 1984). Além disso, Talling (1987), Hecky \& Kling (1987), Jacobsen \& Simonsen (1993) e Huszar et al. (2000), discutem que o regime de estratificação da coluna d'água também favorece o desenvolvimento das cianobactérias, pois a presença dos aerótopos possibilitam a sua migração na coluna d'água ocupando a zona eufótica para melhor aproveitamento de luz e nutrientes, concordando com os resultados obtidos neste estudo.

Ainda, segundo Komárek \& Kling (1991) e Huszar et al. (2000), além das estratégias adaptativas das cianobactérias e do regime de mistura da água, as condições de elevada trofia do sistema favorecem acentuadamente o estabelecimento de florações de espécies desse grupo em regiões tropicais. Assim, no Lago das Garças, os efeitos da eutrofização crescente propiciam condições ótimas de crescimento para as cianobactérias, principalmente, nos meses mais quentes.

Elevadas densidades da cianobactéria Sphaerocavum brasiliense ocorreram na primavera (setembro/97; figura 8b). Nogueira (1997), Ramirez \& Bicudo (2002, 2003), verificaram aumento da densidade de Cyanobacteria em decorrência de floração de Microcystis aeruginosa, durante a primavera e início de verão neste mesmo lago em anos anteriores (19931994). Com base nos resultados obtidos no presente estudo, podemos afirmar que houve substituição da cianobactéria $M$. aeruginosa, formadora de floração durante a primavera, por $S$. brasiliense nessa mesma 

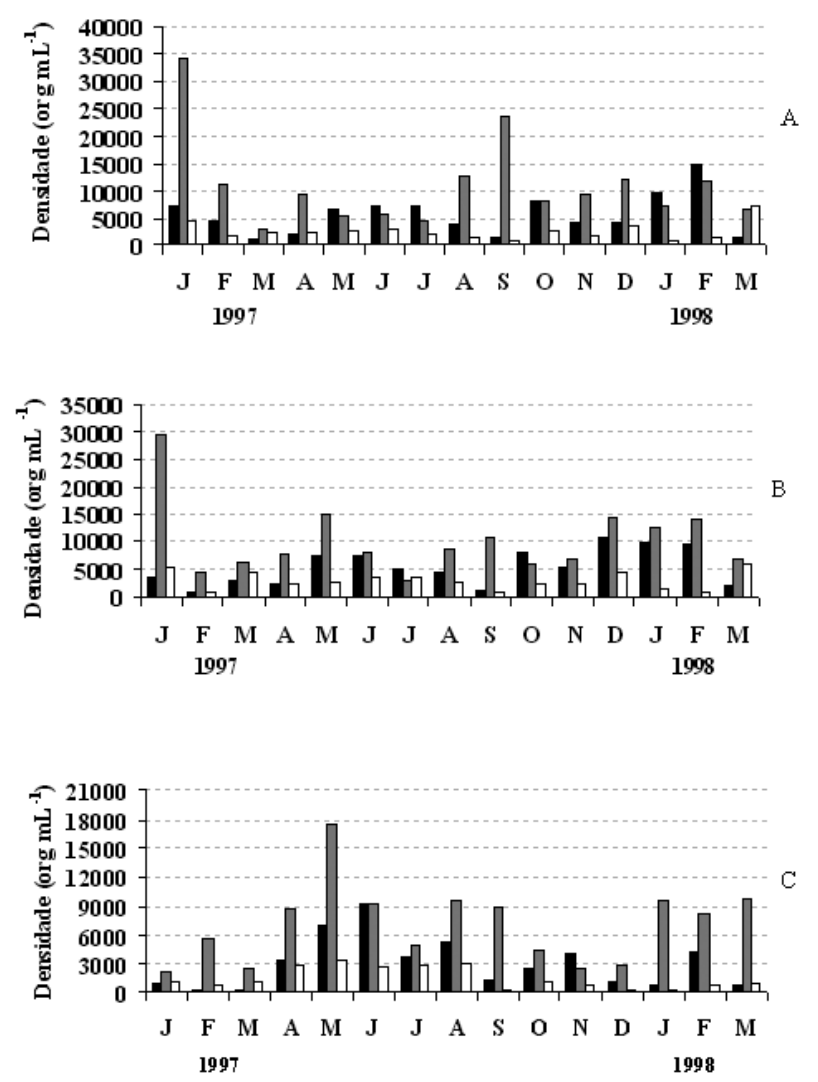

Figura 5. Variação temporal da densidade $\left(\operatorname{org} \mathrm{mL}^{-1}\right)$ das classes fitoplanctônicas do Lago das Garças, na superfície (a), 2 metros (b) e fundo (c) durante o período estudado. $\square=$ Chlorophyceae; $\square=$ Cyanobacteria; $\square=$ outros (Bacillariophyceae, Chrysophyceae, Dinophyceae, Euglenophyceae, Xanthophyceae e Zygnemaphyceae).

época do ano. Essa substituição de M. aeruginosa por $S$. brasiliense também foi confirmada por Fonseca (2005), para o Lago das Garças, cujas amostragens foram feitas no mesmo ano do nosso estudo.

A análise de componentes principais (ACP) realizada para as espécies fitoplanctônicas abundantes e/ ou dominantes resumiu $38 \%$ da variabilidade total dos dados (tabela 3, figura 9). No lado positivo do eixo 1 , foram agrupadas as unidades amostrais do verão (fundo) (dezembro/97 a março/98), associadas a elevadas densidade das cianobactérias Merismopedia glauca e Geitlerinema unigranulatum; enquanto que no lado negativo do eixo 1 , foram agrupadas as unidades amostrais da primavera (outubro-novembro/97), associadas a elevadas densidades de Chlorococcum infusionum (Chlororophyceae), Rhodomonas lacustris (Cryptophyceae) e Trachelomonas volvocina (Euglenophyceae), Aphanocapsa incerta (Cyanobacteria).

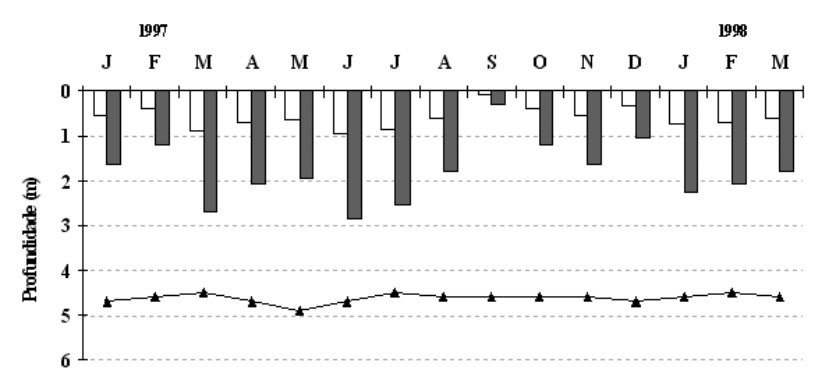

Figura 6. Variação da transparência (m), da zona eufótica (m) e da profundidade $(\mathrm{m})$ na estação de coleta no período estudado ( $\square=$ transparência; $\square=$ zona eufótica; $\square=$ profundidade máxima).

No lado positivo do eixo 2, foram agrupadas as unidades amostrais referentes ao inverno e primavera (junho, julho agosto, setembro e outubro) associadas a elevadas densidades das clorofíceas Scenedesmus quadricauda, S. bijugus e Crucigeniella crucifera. No lado negativo do eixo 2 agruparam-se as unidades amostrais do verão (janeiro a março/97) associadas às maiores densidades de Planktothrix agardhii e Cylindrospermopsis raciborskii.

Chlorophyceae foi a classe abundante nos períodos de outono-inverno (maio, junhojulho/97) na superfície (figura 5). Nesse período, as desestratificações térmicas da coluna d'água (figura 2) podem ter favorecido o desenvolvimento das espécies Chlorococcum infusionum (Schrank) Meneghini, Crucigenia tetrapedia (Kirsch.) West \& West, Crucigeniella crucifera (Wolle) Komárek e Scenedesmus quadricauda (Turpin) Brébisson. Tais ocorrências podem estar aliadas à maior disponibilidade de nutrientes provenientes da ressuspensão do fundo, como pode ser observado pela alta concentração de nitrato em junho-julho/97, aos valores mais baixos de $\mathrm{pH}$ (tabela 2 ) e aos maiores valores de transparência (figura 6) decorrentes da diminuição das cianobactérias, corroborando os resultados obtidos por outros autores (Margalef 1983, Shapiro 1990). Branco \& Senna (1996a) também observaram aumento desse grupo durante a época de seca no reservatório Paranoá (DF). Beyruth (1996, 2000), na Represa Guarapiranga e Calijuri et al. (2002), na Represa de Barra Bonita, ambas no Estado de São Paulo, mostraram maior abundância de Chlorophyceae associada ao período de circulação da água, elevada transparência e concentrações mais altas de nutrientes, particularmente nitrato e fosfato. 


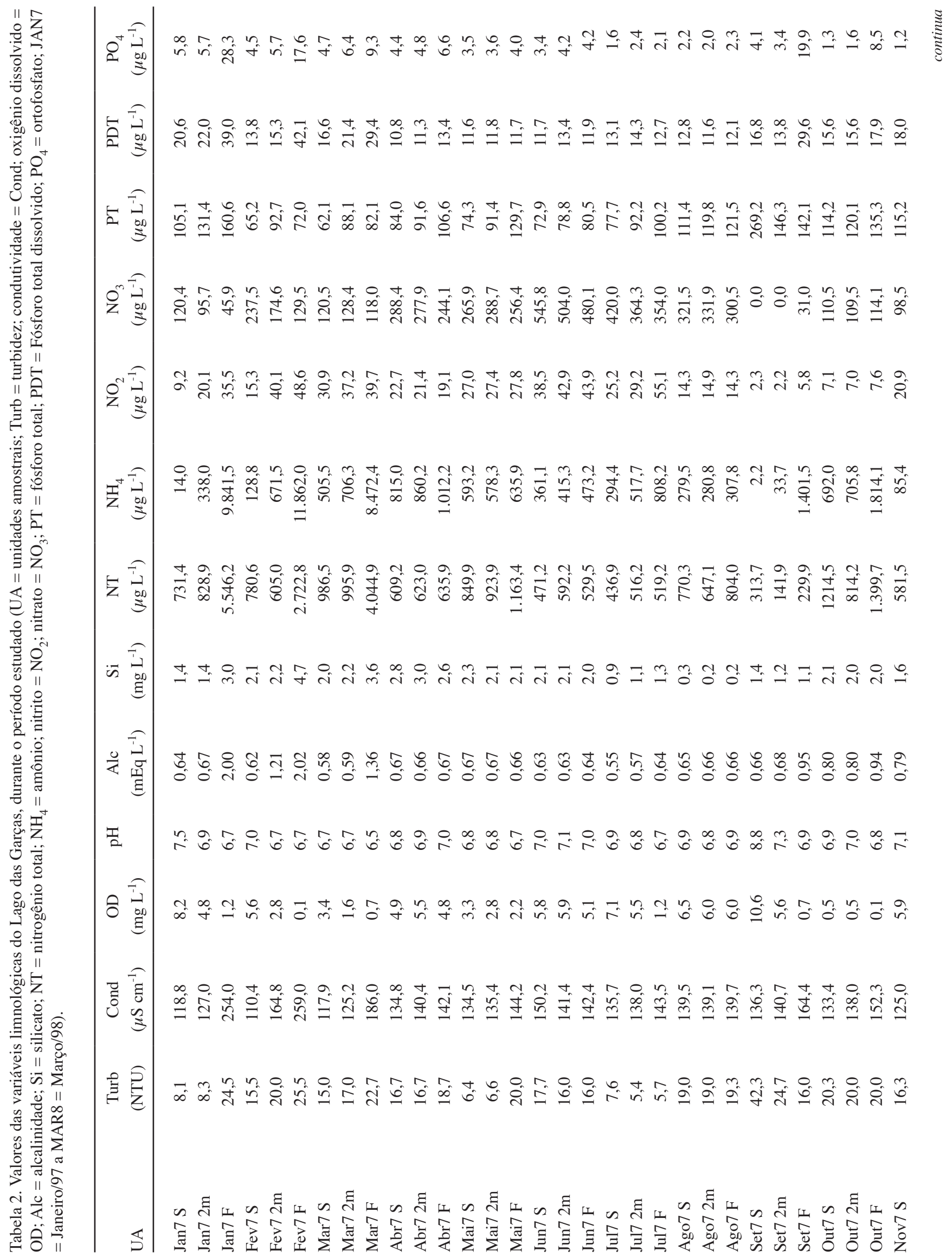




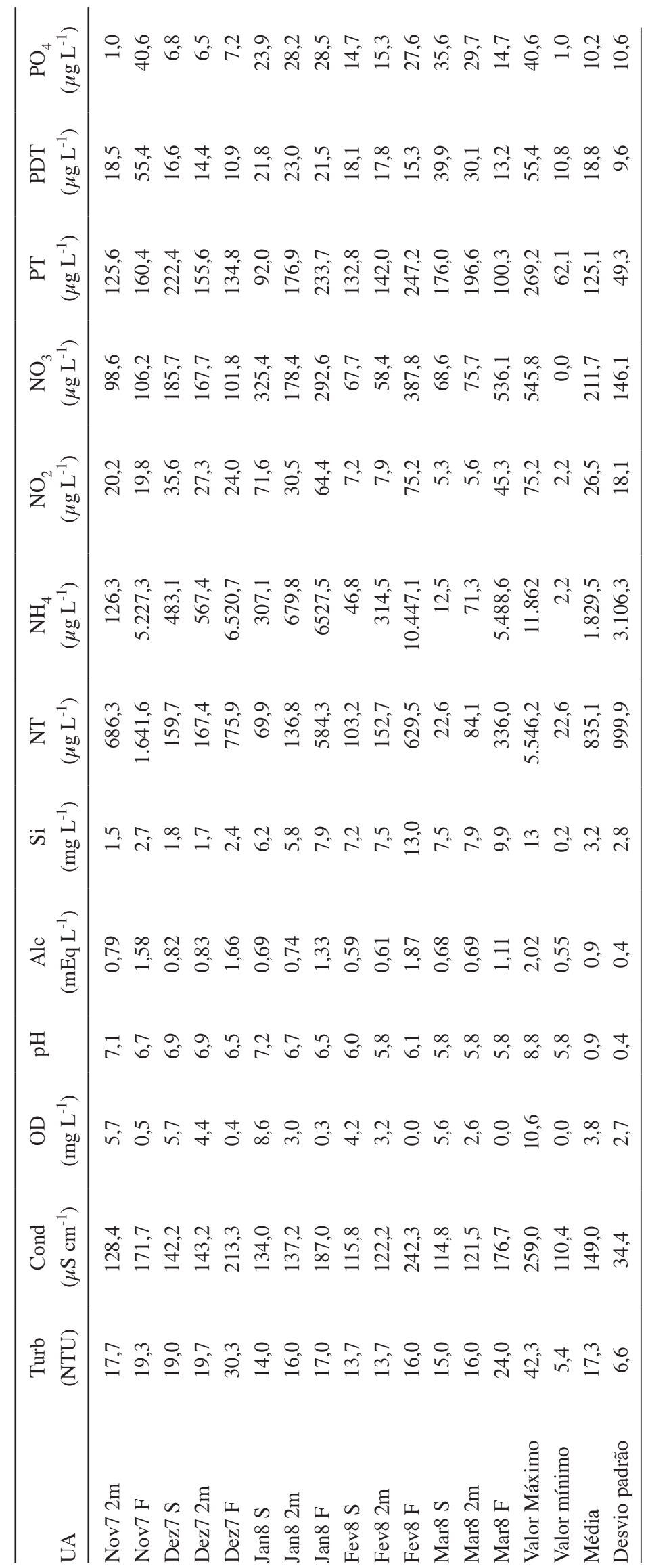


Tabela 3. Coeficientes de correlação de Pearson entre as espécies dominantes e abundantes com os dois primeiros eixos da ACP (valores em negrito correspondem aos táxons que tiveram maior correlação com os eixos, acima de 0,5).

\begin{tabular}{|c|c|c|c|}
\hline \multirow[b]{2}{*}{ Táxons } & \multirow[b]{2}{*}{ Abreviações } & \multicolumn{2}{|c|}{ Componentes Principais } \\
\hline & & Eixo 1 & Eixo 2 \\
\hline Aphanocapsa delicatissima West \& G.S. West & Aphde & 0,269 & 0,475 \\
\hline A. incerta (Lemmermann) Cronberb \& Komárek & Aphce & $-0,813$ & $-0,030$ \\
\hline Closterium sp. & Ctsp & $-0,043$ & $-0,357$ \\
\hline Chlorella vulgaris Beijerink & Chlvug & $-0,411$ & $-0,109$ \\
\hline Chlorococcum infusionum (Schrank) Meneghini & Cinfs & $-0,687$ & 0,097 \\
\hline Crucigenia tetrapedia (Kirchner) West \& G.S. West & Crtetr & $-0,370$ & 0,286 \\
\hline Crucigeniella crucifera (Wolle) Komárek & Cruci & $-0,066$ & 0,758 \\
\hline Cryptomonas brasiliensis Castro, C. Bicudo \& D. Bicudo & Crbras & $-0,414$ & 0,363 \\
\hline Cryptomonas curvata Ehrengerg emend. Penard & Crcurv & $-0,485$ & $-0,051$ \\
\hline Cylindrospermopsis raciborskii (Wolosz.) Seenayya \& Subba Raju & Cski & $-0,095$ & $-0,658$ \\
\hline Didymocystis planctonica Korshikov & Dplanc & $-0,422$ & 0,299 \\
\hline Geitlerinema unigranulatum (R.N. Singh) Komárek \& Azevedo & Ggran & 0,805 & 0,114 \\
\hline Golenkiniopsis solitaria (Korshikov) Korshikov & Gosol & $-0,354$ & $-0,405$ \\
\hline Merismopedia elegans A. Braun ex Kützing & Meleg & $-0,344$ & 0,282 \\
\hline M. glauca (Ehrengerg) Kützing & Mgla & 0,781 & 0,127 \\
\hline M. tenuissima Lemmermann & Mten & 0,199 & 0,490 \\
\hline Microcystis aeruginosa (Kützing) Kützing & Maer & $-0,272$ & $-0,322$ \\
\hline Monoraphidium contortum (Thuret) Komárkova-Legnerová & Mcont & 0,080 & 0,346 \\
\hline Planktothrix agardii (Gomont) Anagnostidis \& Komárek & Pgar & $-0,200$ & $-0,677$ \\
\hline Rhodomonas lacustris Pascher \& Ruttner & Rholac & $-0,625$ & $-0,001$ \\
\hline Scenedesmus arcuatus (Lemmermann) Lemmermann & Scarc & 0,583 & 0,302 \\
\hline S. bijugus (Turpin) Kützing & Scbij & 0,304 & 0,567 \\
\hline S. quadricauda (Turpin) Brébisson & Scqua & $-0,307$ & 0,725 \\
\hline Sphaerocavum brasiliense Azevedo \& Sant'Anna & Svum & $-0,466$ & 0,370 \\
\hline Synechococcus nidulans (Pringsheim) Komárek & Snid & $-\mathbf{0 , 5 3 8}$ & 0,178 \\
\hline Trachelomonas volvocina Ehrenberg & Tvolv & $-0,822$ & $-0,148$ \\
\hline & & $21 \%$ & $17 \%$ \\
\hline
\end{tabular}

Espécies de outras classes fitoplanctônicas também foram favorecidas durante o período anteriormente mencionado: Synedra acus Kützing (Bacillariophyceae), Cryptomonas curvata Ehrenberg emend. Pernard e Rhodomonas lacustris Pascher \& Ruttner (Cryptophyceae) e Trachelomonas volvocina (Euglenophyceae). Moura (1996) e Sant'Anna et al. (1997) verificaram maior ocorrência dessas classes no período seco, associada a baixos valores de $\mathrm{pH}$, de temperatura e de turbidez, como também pode ser verificado neste estudo.

As classes Dinophyceae, Chrysophyceae, Xanthophyceae e Zygnemaphyceae contribuíram pouco para a densidade fitoplanctônica total, o que também foi observado por Moura (1996), Sant'Anna et al. (1997) e Tucci (2002) que verificaram baixa 
representatividade dessas classes em virtude das condições eutróficas do lago das Garças. Segundo Pollingher (1988), tais grupos de algas geralmente estão associados a condições oligotróficas, tendendo a desaparecer quando outros grupos fitoplanctônicos desenvolvem-se.

Elevados valores de diversidade e baixos de dominância foram registrados nos meses de outonoinverno influenciados, muito provavelmente, pela mistura da coluna d'água registrada neste período, que favoreceu o desenvolvimento de espécies capazes de sobreviver às condições de instabilidade térmica da coluna d'água. Por outro lado, a elevada abundância de Sphaerocavum brasiliense, em setembro/97 (superfície) refletiu no alto índice de dominância e nos baixos valores de diversidade, riqueza e equitabilidade (figuras 10, 11).

Com base nos nossos resultados e nos trabalhos de Ramírez (1996), Moura (1996), Sant'Anna et al. (1997) e Fonseca (2005), há uma tendência de elevada dominância e baixos riqueza, diversidade e equitabilidade na primavera e uma situação inversa nos meses de outono-inverno no Lago das Garças.

Os parâmetros sanitários estudados, demanda bioquímica (DBO), demanda química de oxigênio (DQO), coliformes totais e coliformes fecais, puderam ser utilizados como informações complementares, pois em virtude do reduzido número de amostras (duas épocas do ano), não foi possível fazer correlações estatísticas de tais dados (Doria Filho 1999).

Segundo APHA (1989) e Ceballos (1995) a presença de coliformes, principalmente coliformes fecais, indica contaminação por esgoto doméstico e sua quantidade depende da carga fecal que é lançada e do tempo de residência da água. Observou-se no Lago das Garças que os menores valores médios de coliformes totais e fecais (tabela 4), ocorreram no período de inverno (seca) porque provavelmente não houve grande aporte de matéria orgânica alóctone pelo baixo escoamento superficial e também por ser um período onde foi registrado mistura da coluna d'água. Por outro lado, na época do verão (período de chuva), observou-se aumento nos valores médios desses microorganismos (tabela 4), evidenciando o aumento no aporte de material orgânico para o lago. Carmo et al. 2002, estudando o aporte de nitrogênio e fósforo de origem antropogênica para o mesmo lago, identificaram sete entradas pontuais de contribuição orgânica, sendo que duas delas foram as mais expressivas em termos de $\mathrm{N}$ e P. Tais entradas correspondem a despejos de esgotos provenientes
Tabela 4. Valores absolutos e valores médios $(n=5)$ de densidade (NMP org $100 \mathrm{~mL}^{-1}$ ) de coliformes totais (CT) e coliformes fecais (CF) no Lago das Garças no período de seca e chuva.

\begin{tabular}{lrc}
\hline Período Inverno (Seca) & CT & CF \\
\hline $28 / 07 / 1997$ & 5.000 & 340 \\
$05 / 08 / 1997$ & 8.000 & 210 \\
$11 / 08 / 1997$ & 5.000 & 900 \\
$19 / 08 / 1997$ & 7.000 & 3.000 \\
$26 / 08 / 1997$ & 22.000 & 5000 \\
\hline Média & 9.400 & 1.890 \\
\hline Período de Verão (Chuva) & $\mathrm{CT}$ & $\mathrm{CF}$ \\
\hline 09/02/1998 & 30.000 & 3.000 \\
09/03/1998 & 1.300 & 1.300 \\
$16 / 03 / 1998$ & 13.000 & 13.000 \\
$23 / 03 / 1998$ & 2.300 & 1.300 \\
$30 / 03 / 1998$ & 8.000 & 3.000 \\
\hline Média & 10.920 & 4.320 \\
\hline
\end{tabular}

da Fundação Parque Zoológico e da Secretaria de Agricultura e Abastecimento do Estado de São Paulo. É importante considerar que a contribuição de carga fecal no Lago das Garças deve-se aos dejetos de humanos e também de animais.

Segundo Carmo (2000), em julho-agosto/97 as concentrações de nitrogênio e fósforo foram menores do que em fevereiro-março/98. No presente trabalho, os resultados obtidos para coliformes totais e fecais (figura 12) seguiram o mesmo padrão, o que, certamente, indica a associação dos coliformes com as cargas de fósforo e nitrogênio.

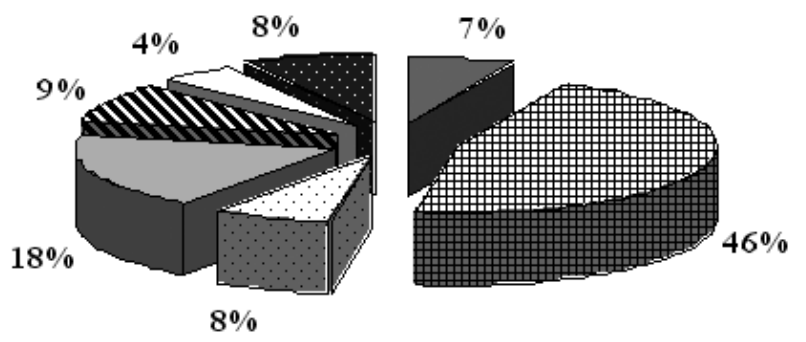

Figura 7. Porcentagem de contribuição das classes fitoplanctônicas para a riqueza total do Lago das Garças, durante o período estudado $[\square=$ Bacillariophyceae; 郁 = Chlorophyceae; $\because \because \cdot]=$ Chrysophyceae; $\square$ = Cyanobacteria; $\mathbf{W}$ = Euglenophyceae; $\square=$ Zygnemaphyceae, $\because$ = outros (Cryptophyceae, Dinophyceae e Xanthophyceae)]. 

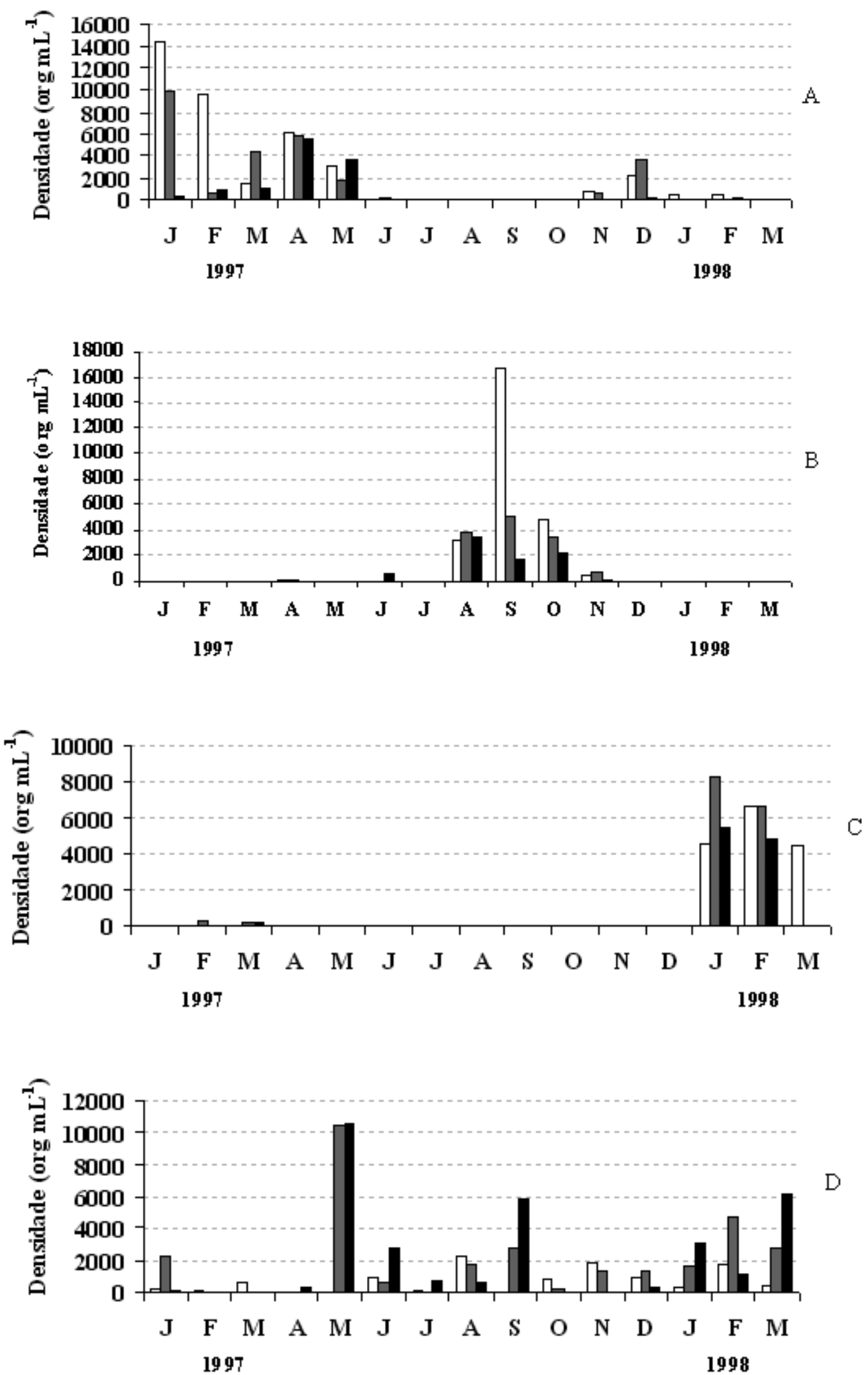

Figura 8. Variação espacial e temporal da densidade $\left(\right.$ org $\left.\mathrm{mL}^{-1}\right)$ das espécies dominantes: Cylindrospermopsis raciborskii (a), Sphaerocavum brasiliense (b), Merismopedia glauca (c) e Merismopedia tenuissima (d) no Lago das Garças, durante o período estudado $(\square=$ superfície; $\square=2$ metros; $\boldsymbol{\square}=$ Fundo). 


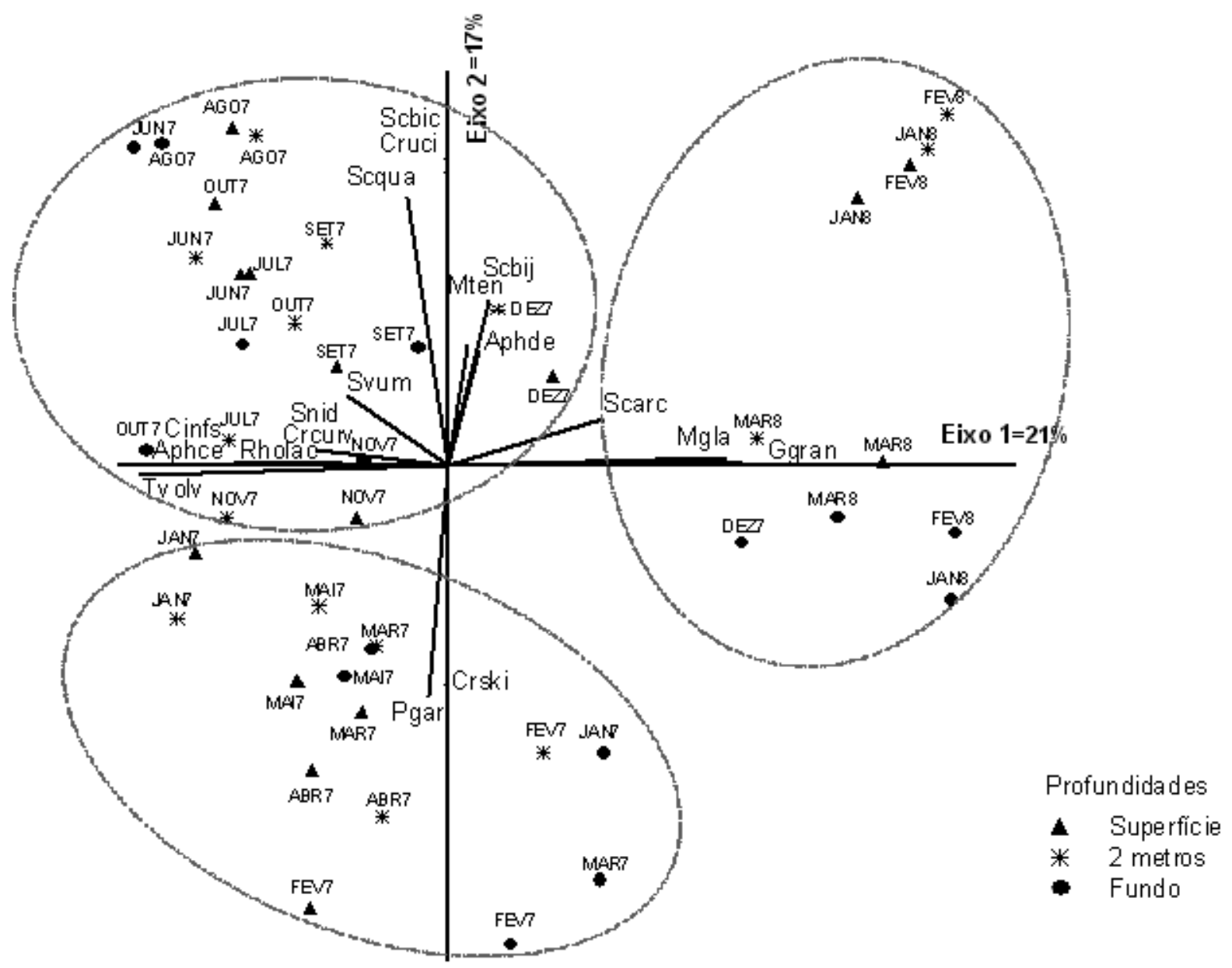

Figura 9. Biplot da ACP (eixos 1 e 2) das unidades amostrais (abreviações: JAN7 a MAR8), em três profundidades (superfície, 2 m e fundo) no Lago das Garças, em função das espécies fitoplanctônicas dominantes e abundantes. (Abreviações conforme tabela 3 ).

Demanda bioquímica e demanda química de oxigênio são parâmetros que permitem inferir a quantidade de matéria orgânica presente no ambiente, através da medida do consumo de oxigênio por microrganismos e pela oxidação total da matéria orgânica, respectivamente (Pivelli 1998). Considerando o primeiro período de coleta (setembro e outubro/97), os maiores valores registrados de DBO e DQO (figura 14) devem-se provavelmente às baixas precipitações ocorridas (figura 3), ao maior tempo de residência da água e ao aumento da autodepuração, ou seja, a ação decompositora dos microrganismos sobre a matéria orgânica, com conseqüente aumento do consumo de oxigênio. ADQO apresentou valores mais elevados que a DBO, pois, como já foi mencionado, neste último processo há oxidação total de material orgânico. A quantidade de matéria orgânica presente no Lago das Garças no mês de setembro, quando houve um pico nas concentrações de clorofila- $a$ (figura 4), pode também ter influenciado o maior valor de turbidez, que segundo Ceballos (1995), tem correlações positivas significativas com coliformes fecais, estreptococos fecais e clorofila- $a$, muito provavelmente, pela maior concentração desses elementos nas camadas superficiais da coluna d'água.

No segundo período, os resultados obtidos para DBO não puderam ser utilizados devido a problemas metodológicos (diluição insuficiente das amostras, favorecendo a ação dos organismos decompositores, o que demandou elevado consumo de oxigênio durante o período de incubação das amostras). Quanto à DQO, os valores mais baixos registrados (figura 13), devem-se provavelmente ao efeito diluidor das chuvas e consequiente diminuição do tempo de residência da água, o que favoreceria a diluição de compostos degradáveis e sua saída mais rápida do sistema. 

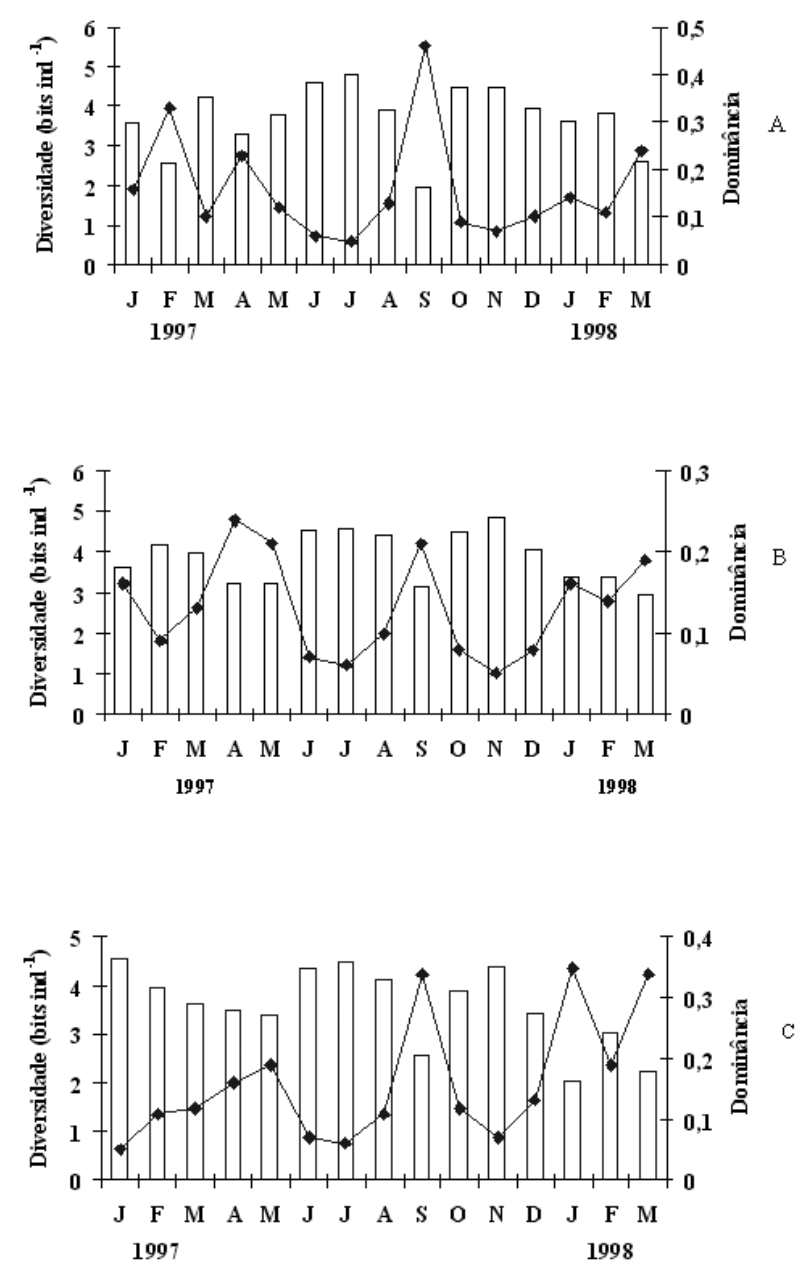

Figura 10. Variação dos índices de diversidade (bits ind ${ }^{-1}$ ) e dominância na superfície (A), 2 metros (B) e fundo (C) do Lago das Garças, durante o período de estudo $(\square=$ diversidade, $-\bullet=$ dominância).

Considerando a resolução Conama (2005) $n^{\circ}$ 357, o Lago das Garças pode ser classificado como de águas de classe 4, uma vez que não é utilizado para abastecimento público mas, principalmente para "harmonia paisagística", apresentando valores de O.D. superiores a 2,0 $\mathrm{mg} \mathrm{L}^{-1}$ (exceto no fundo do lago) e pH entre 6 e 9. A resolução não estabelece valores de coliformes totais e fecais, DBO e DQO para águas de classe 4. Entretanto, deveria ser considerada a utilização do lago também para preservação do equilíbrio natural, proteção das comunidades aquáticas e irrigação de parques e jardins. Contudo, isso só será possível quando as medidas que visem a sua recuperação e preservação sejam efetivamente implantadas.
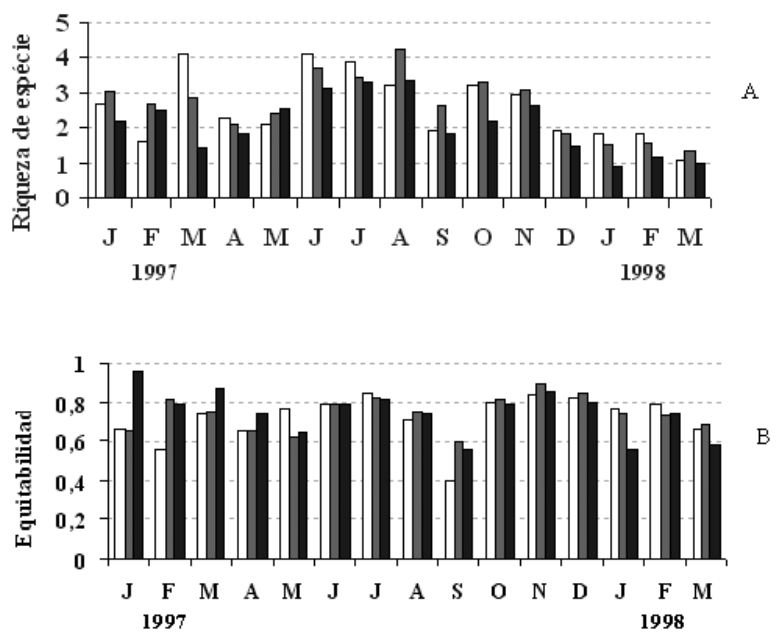

Figura 11. Variação do Índice de Riqueza (A) e do Índice de Equitabilidade (B) no Lago das Garças, durante o período estudado ( $\square$ = superfície; $\square=2$ metros; $\boldsymbol{\square}=$ fundo).

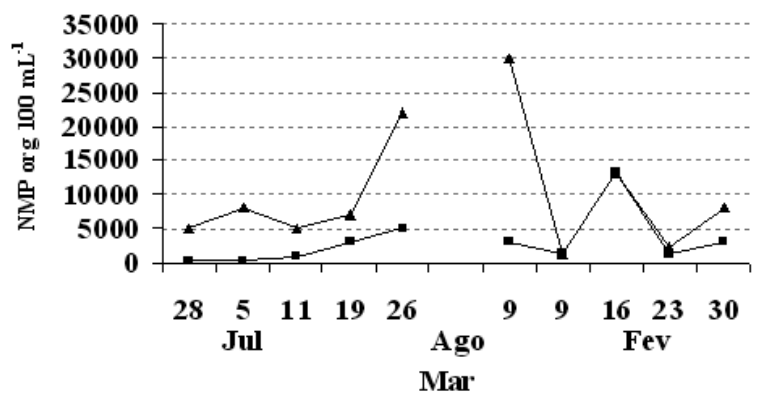

Figura 12. Variação da densidade (NMP org $100 \mathrm{~mL}^{-1}$ ) de coliformes totais e fecais, no Lago das Garças, durante o período estudado $(\multimap=$ Coliforme total; $\longrightarrow-=$ Coliforme fecal $)$.

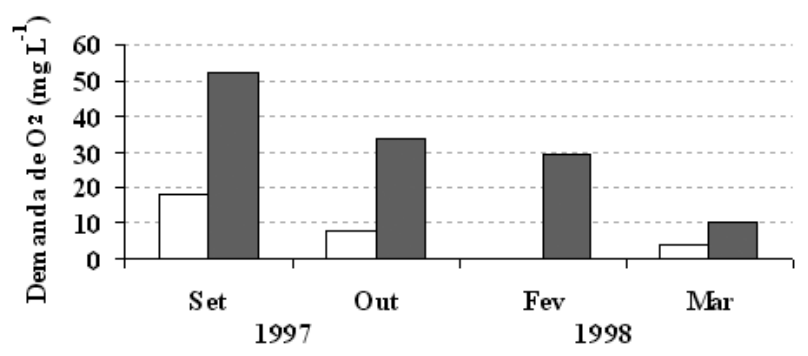

Figura 13. Variação dos valores de demanda de $\mathrm{O}_{2}\left(\mathrm{mg} \mathrm{L}^{-1}\right)$, no Lago das Garças, durante o período estudado $(\square=\mathrm{DBO}, \quad \square=$ DQO). 


\section{Agradecimentos}

A primeira autora agradece ao $\mathrm{CNPq}$ a bolsa de mestrado recebida (Processo 13.6093/1999-0) e à Dra. Denise de Campos Bicudo pelo auxílio nas análises estatísticas. Este trabalho faz parte do projeto "Tipologia, monitoramento e recuperação dos corpos d'água da Reserva Biológica do Parque Estadual das Fontes do Ipiranga, São Paulo" (processo CNPq 520745/96-5).

\section{Literatura citada}

APHA. 1989. Standard methods for examination of water and wastewater. 17th. American Public Health Association, Washington.

Azevedo, M.T.P. \& Sant'Anna, C.L. 1999. Coelosphaerium evidenter-marginatum, a new planktonic species of Cyanophyceae/Cyanobacteria from São Paulo State, Southeastern Brazil. Algological Studies 94: 35-43.

Azevedo, S.M.F.O., Evans, W.R., Carmichael, W.W. \& Namikoshi, M. 1994. First report of microcystins from Brazilian isolate of cyanobacterium Microcystis aeruginosa. Journal of Applied Phycology 6: 261265.

Beyruth, Z. 1996. Comunidade fitoplanctônica da Represa de Guarapiranga: 1991-92. Aspectos ecológicos, sanitários e subsídios para reabilitação da qualidade ambiental. Tese de Doutorado, Faculdade de Saúde Pública, São Paulo.

Beyruth,Z. 2000. Periodic disturbances, trophic gradient and phytoplankton characteristics related to cyanobacterial growth in Guarapiranga Reservoir, São Paulo State, Brazil. Hydrobiologia 424: 51-65.

Bicudo, C.E.M., Ramírez, J.J.R., Tucci, A. \& Bicudo, D.C. 1999a. Dinâmica de populações fitoplanctônicas em ambiente eutrofizado: o Lago das Garças, São Paulo. In: R. Henry (ed.). Ecologia de reservatórios: estrutura, funções e aspectos sociais. Fundibio, Botucatu, pp. 449-508.

Bicudo, C.E.M., Carmo, C.F., Bicudo, D.C., Henry, R., Pião, A.C.S., Santos, C.M. \& Lopes, M.R.M. 2002. Morfologia e morfometria de três reservatórios do PEFI, Capítulo 9. In: D.C. Bicudo, M.C. Forti \& C.E.M. Bicudo (orgs.). Parque Estadual das Fontes do Ipiranga (PEFI): unidade de conservação que resiste à urbanização de São Paulo. Secretaria do Meio Ambiente do Estado de São Paulo, São Paulo, pp. 143-160.

Bicudo, D.C., Tucci, A., Ramírez, J.J.R., Carmo, C.F., Nogueira, N.M.C. \& Bicudo, C.E.M. 1999b. Escala de amostragem e variabilidade de fatores limnológicos em reservatório eutrofizado: (Lago das Garças, São Paulo). In: R. Henry (ed.). Ecologia de reservatórios: estrutura, funções e aspectos sociais. Fundibio, Botucatu, pp. 409-448.

Branco, C.W.C. \& Senna, P.A.C. 1996. Phytoplankton composition, community structure and seasonal changes in a tropical reservoir (Paranoá Reservoir, Brazil). Algological Studies 81: 69-84.

Calijuri, M.C., Santos, A.C. A. \& Jati, S. 2002. Temporal changes in the phytoplankton community structure in tropical and eutrophic reservoir (Barra Bonita, SP, Brazil). Journal of Plankton Research 24: 617-634.

Carmo, C.F. 2000. Aporte de nutrientes, nitrogênio e fósforo, e sua relação com os impactos antropogênicos em um lago urbano, São Paulo, SP, Brasil. Dissertação de mestrado, Escola de Engenharia de São Carlos, São Carlos.

Carmo, C.F., Henry, R., Bicudo, D.C. \& Bicudo, C.E.M. 2002. A degradação nos reservatórios do PEFI. In: D.C. Bicudo, M.C. Forti \& C.E.M. Bicudo (eds.). Parque Estadual das Fontes do Ipiranga (PEFI): unidade de conservação que resiste à urbanização de São Paulo. Secretaria do Meio Ambiente do Estado de São Paulo, São Paulo, pp. 271-296.

Carvalho, M. C. 2003. Comunidade fitoplanctônica como instrumento de biomonitoramento de reservatórios no Estado de São Paulo. Tese de doutorado, Faculdade de Saúde Pública, São Paulo.

Ceballos, B.S.O. 1995. Utilização de indicadores microbiológicos na tipologia de ecossistemas aquáticos do trópico semi-árido. Tese de doutorado, Universidade de São Paulo, São Paulo.

CETESB. 2000. Relatório das águas interiores do estado de São Paulo, 1999. Relatório Técnico. CETESB, São Paulo.

Cole, G. 1983. Textbook of limnology. C.V. Mosby, London.

CONAMA. 2005. Resolução no 357, de 17 de março de 2005. Diário Oficial da União, Brasília, 18/03, p.58.

Crossetti, L.O. 2006. Estrutura e dinâmica da comunidade fitoplanctônica no período de oito anos em ambiente eutrófico raso (Lago das Garças), Parque Estadual das Fontes do Ipiranga, São Paulo. Tese de doutorado, Universidade de São Paulo, Ribeirão Preto.

Crossetti, L.O. \& Bicudo, C.E.M. 2005a. Structural and functional phytoplankton responses to nutrient impoverishment in mesocosms placed in a shallow eutrophic reservoir (Garças Pond), São Paulo, Brazil. Hydrobiologia 541: 71-85.

Crossetti, L.O. \& Bicudo, C.E.M. 2005b. Effects of nutrient impoverishment on phytoplankton biomass: a mesocosms experimental approach in a shallow eutrophic reservoir (Garças Pond), São Paulo, southeast Brazil. Revista Brasileira de Botânica 28: 95-108.

Doria Filho, U. 1999. Introdução à bioestatística: para simples mortais. Negócio Editora, São Paulo. 
Fernandes, A.J., Reis, L.A.M., Oda, G.H. \& Iritani, M.A. 2002. Caracterização do meio físico. In: D.C. Bicudo, M.C. Forti \& C.E.M. Bicudo (orgs.). Parque Estadual das Fontes do Ipiranga (PEFI): unidade de conservação que resiste à urbanização de São Paulo. Secretaria do Meio Ambiente do Estado de São Paulo, São Paulo, pp. 49-62.

Fonseca, B. M. 2005. Diversidade fitoplanctônica como discriminador ambiental em dois reservatórios rasos com diferentes estados tróficos no Parque Estadual das Fontes do Ipiranga, São Paulo, SP. Tese de doutorado, Universidade de São Paulo, São Paulo.

Golterman, H.L. \& Clymo, R.S. 1969. Methods for chemical analysis of freshwater. Blackwell Scientific Publications, Oxford.

Golterman, H.L., Clymo, R.S. \& Ohmstad, M.A.M. 1978. Methods for physical and chemical analysis of freshwater. 2 ed. Blackwell Scientific Publications, Oxford.

Hecky, R.E. \& Kling, H.J. 1987. Phytoplankton ecology of the great lakes in the rift valleys of Central Africa. Archiv fur Hydrobiologie: Beihefte: Ergebnisse der Limnologie 25: 197-228.

Honda, R. \& Azevedo, M.T.P. 2004. Estudos taxonômicos em culturas de Cyanobacteria provenientes de um reservatório oligotrófico no Parque Estadual das Fontes do Ipiranga (PEFI), São Paulo, SP, Brasil. Hoehnea 31: 151-169.

Huszar, V.L.M., Silva, L.H.S., Marinho, M.M., Domingos, P. \& Sant'Anna, C.L. 2000. Cyanoprokaryote assemblages in eight productive tropical Brazilian waters. In: C.S. Reynolds, M. Dokulil \& J. Padisák (eds.). The trophic spectrum revisited: The influence of trophic state on the assembly of phytoplankton communities. Academic Publishers, Dordrecht, pp. 67-77.

Jacobsen, B.A. \& Simonsen, P. 1993. Disturbance events affecting phytoplankton biomass, composition and species diversity in a shallow, eutrophic, temperate lake. Hydrobiologia 249: 9-14.

Komárek, J. 2003. Coccoid and colonial Cyanobacteria. In: J.D.Wehr \& R.G. Sheath (eds.). Freshwater algae of North America: ecology and classification. Academic Press, San Diego, pp. 59-116.

Komárek, J. \& Kling, H. 1991. Variation in six planktonic cyanophyte genera in Lake Victoria (East Africa). Algological Studies 61: 21-45.

Lobo, E. \& Leigthon, G. 1986. Estruturas de las fitocenosis planctónicas de los sistemas de desembocaduras de rios y esteros de la zona central de Chile. Revista de Biologia Marinha 22: 1-29.

Mackereth, F.J.H., Heron, J. \& Talling, J.F. 1978. Water analysis: some revised methods for limnologists. Scientific Publication 36. Freshwater Biological Association, Cumbria.
Margalef, R. 1958. Temporal succession and spatial heterogeneity in phytoplankton. In: A.A. BuzzatiTraverso (ed.). Perspectives in marine biology. University of California Press, Berkeley, pp. 323-349.

Margalef, R. 1983. Limnologia. Omega, Barcelona.

Margalef, R. 1991. Teoria de los sistemas ecológicos. Publicación de la Universitat de Barcelona, Barcelona.

McCune, B. \& Mefford, M.J. 1997. PC-ord. Multivariate analysis of ecological data, version 3.0. MgM Software Design, Gleneden Beach.

Moura, A.T.N. 1996. Estrutura e dinâmica da comunidade fitoplanctônica numa lagoa eutrófica, São Paulo, SP, Brasil, a curtos intervalos de tempo: comparação entre épocas de chuva e seca. Dissertação de mestrado, Universidade Estadual Paulista, Rio Claro.

Nogueira, N.M.C. 1997. Dinâmica populacional de Microcystis aeruginosa Kützing (Cyanophyceae/ Cyanobacteria) ao longo de um ano no Lago das Garças, São Paulo, SP, Brasil. Dissertação de mestrado, Universidade Estadual Paulista, Rio Claro.

Pielou, E.C. 1975. Ecological diversity. John Wiley \& Sons, New York.

Pinto-Coelho, R.M., Coelho, M.M., Espírito-Santo, M.M. \& Cornelissen, T.G. 1999. Efeitos da eutrofização na estrutura da comunidade planctônica na lagoa da Pampulha. In: R. Henry (ed.). Ecologia de reservatórios: estrutura, funções e aspectos sociais. Fundibio, Botucatu, pp. 551-72.

Piveli, R.P. 1998. Qualidade das águas: Apostila da disciplina "Qualidade Ambiental I". Faculdade de Saúde Pública, São Paulo.

Pollingher, U. 1988. Freshwater armored dinoflagellates: growth, reproduction, strategies, and population dynamics. In: C.G. Sandgren (ed.). Growth and reproductive strategies of freshwater phytoplankton. Cambridge University Press, Cambridge, pp. 134174.

Ramírez R., J.J. 1996. Variações espacial, vertical e nictemeral da estrutura da comunidade fitoplanctônica e variáveis ambientais em quatro dias de amostragem de diferentes épocas do ano no Lago das Garças, São Paulo. Tese de doutorado, Universidade de São Paulo, São Paulo.

Ramírez R., J.J. \& Bicudo, C.E.M. 2002. Variation of climatic and physical co-determinants of phytoplankton community in four nictemeral sampling days in a shallow tropical reservoir, southeastern Brazil. Brazilian Journal of Biology 62: 1-14.

Ramírez R., J.J. \& Bicudo, C.E.M. 2003. Diurnal, vertical and among sampling days variation of dissolved $\mathrm{O}_{2}$, $\mathrm{CO}_{2}$, and $\mathrm{pH}$ in a shallow, tropical reservoir (Garças reservoir, São Paulo, Brazil). Acta Limnologica Brasiliensia 15: 19-30. 
Ramírez R., J.J. \& Bicudo C.E.M. 2005. Diurnal and spatial (vertical) dynamics of nutrients $(\mathrm{N}, \mathrm{P}, \mathrm{Si})$ in four sampling days (summer, fall, winter, and spring) in a tropical shallow reservoir and their relationships with the phytoplankton community. Brazilian Journal of Biology 65: 141-157.

Reynolds, C.S. 1984. Phytoplankton periodicity: the interations of form, function and environmental variability. Freshwater Biology 14: 111-142.

Sant'Anna, C.L., Azevedo, M.T.P. \& Sormus, L. 1989. Fitoplâncton do Lago das Garças, Parque Estadual das Fontes do Ipiranga, São Paulo, SP, Brasil: estudo taxonômico e aspectos ecológicos. Hoehnea 16: 89-131.

Sant'Anna, C.L., Sormus, L., Tucci, A. \& Azevedo, M.T.P. 1997. Variação sazonal do fitoplâncton do Lago das Garças, São Paulo, SP. Hoehnea 24: 67-86.

Santos, P.M. \& Funari, F.L. 2002. Clima local. In: D.C. Bicudo, M.C. Forti \& C.E.M. Bicudo (orgs.). Parque Estadual das Fontes do Ipiranga (PEFI): unidade de conservação que resiste à urbanização de São Paulo. Secretaria do Meio Ambiente do Estado de São Paulo, São Paulo, pp. 29-48.

Sartory,D.P.\& Grobbelaar,J.U. 1984.Extraction of chlorophyll $a$ from freshwater phytoplankton for spectrophotometric analyses. Hydrobiology 114: 177-187.

Shannon, C.E. \& Weaver, W. 1963. The mathematical theory of communication. University of Illinois Press, Urbana.

Shapiro, J. 1990. Current beliefs regarding dominance by blue-greens: The case for the importance of $\mathrm{CO}_{2}$ and $\mathrm{pH}$. Verhandlungen der Internatonalen Vereinigung fur Theorestische und Angewandte Limnologie 24: 38-54.

Shepherd, G.J. 1996. FITOPAC 1: Manual de usuário. Departamento de Botânica, Universidade Estadual de Campinas, Campinas.

Shubert, E. 2003. Nonmotile coccoid and colonial green algae. In: J.D.Wehr \& R.G. Sheath (eds.). Freshwater algae of North America: ecology and classification. Academic Press, San Diego, pp. 253-309.

Simpson, E.H. 1949. Measurement of diversity. Nature 163: 688.

Solorzano, L. 1969. Determination of ammonia in natural waters by the phenolhypochlorite method. Limnology and Oceanography 14: 799-801.
Stevenson, R.J. \& Smol, J.P. 2003. Use of algae in environmental assessments. In: J.D.Wehr \& R.G. Sheath (eds.). Freshwater algae of North America: ecology and classification. Academic Press, San Diego, pp. 775-804.

Strickland, J.D. \& Parsons, T.R. 1960. A manual of sea water analysis. Bulletin of Fisheries Research Board Canada 125: 1-185.

Talling, J.F. 1987. The phytoplankton of Lake Victoria (East África). Archiv fur Hydrobiologie: Beihefte: Ergebnisse der Limnologie 25: 229-256.

Tucci, A. 2002. Sucessão da comunidade fitoplanctônica de um reservatório urbano e eutrófico, São Paulo, SP, Brasil. Tese de doutorado, Universidade Estadual Paulista, Rio Claro.

Tucci, A. \& Sant'Anna, C.L. 2003. Cylindrospermopsis raciborskii (Woloszynska) Seenayya \& Subba Raju (Cyanobacteria): variação semanal e relações com fatores ambientais em um reservatório eutrófico, São Paulo, SP, Brasil. Revista Brasileira de Botânica 26: 97-112.

Tucci, A., Sant'Anna, C.L. Gentil, R.C. \& Azevedo, MT.P. 2006. Fitoplâncton do Lago das Garças, São Paulo, Brasil: um reservatório urbano eutrófico. Hoehnea 33: 147-175.

Tundisi, J.G. 2003. Água no século XXI: enfrentando a escassez. Rima, São Carlos.

Utermöhl, H. 1958. Zur Vervolkommung der quantitativen phytoplankton: methodik. Mitteilungen Internationale Vereinigung für Theoretische und Angewandte Limnologie 9: 1-38.

Valderrama, J.C. 1981. The simultaneous analysis of total nitrogen and total phosphorus in natural waters. Marine Chemical 10: 109-122.

Vercellino, I.S. 2001. Sucessão da comunidade de algas perifíticas em dois reservatórios do Parque Estadual das Fontes do Ipiranga, São Paulo: influência do estado trófico e período climatológico. Dissertação de mestrado, Universidade Estadual Paulista, Rio Claro.

Wetzel, R.G. 1993. Limnologia. Fundação Calouste Gulbenkian, Lisboa.

Wetzel, R.G. \& Likens, G.E. 1991. Limnological analyses. 2 ed. Springer-Verlag, New York. 